\title{
Optimization of continuous arsenic biosorption present in natural contaminated groundwater
}

\author{
Bárbara E Pérez Mora, ${ }^{a, b}$ Sebastián E Bellú, ${ }^{a, b} \odot$ María F Mangiameli, ${ }^{a, b}$ \\ Silvia I García ${ }^{a, b}$ and Juan C González ${ }^{a, b *} \odot$
}

\begin{abstract}
BACKGROUND: Arsenic (As) is a serious water pollution problem in the world. In Argentina, it is related to old volcanic activities; for example, the western region of Santa Fe State has concentrations higher than $0.1 \mathrm{mgAs} \mathrm{L}^{-1}$. In this work, a green, sensitive method was used to determine As concentration, and its removal using chitosan in bed columns was studied. Mathematical models were used to explain sorption, and the process was optimized using statistical methods.

RESULTS: Arsenic quantification was realized with a bespoke modification of the As molybdenum blue method (detection limit $=0.0048 \mathrm{mg} \mathrm{L}^{-1}$, quantification limit $=0.0145 \mathrm{mg} \mathrm{L}^{-1}$ ). Chitosan molar mass, $\mathrm{pH}_{\mathrm{ZPC}}$ and deacetylation degree were $350 \pm 10 \mathrm{kDa}, 6.3 \%$ and $76.2 \%$, respectively. A maximum of $68.5 \%$ was obtained for $\mathrm{As}(\mathrm{V})$ removal at optimum conditions. Raising the bed column height produced an increment in breakthrough times, and the sorption process was favoured using low flow rates. Salinity, phosphate and nitrate concentration reductions were $60 \%, 50 \%$ and $70 \%$, respectively.
\end{abstract}

CONCLUSIONS: Sorption studies have been carried out on groundwater, using columns packed with chitosan for arsenic removal. The process was optimized by a factorial design. Elution profiles were adjusted adequately with mathematical models. The modified analytical technique for arsenic quantification applied in groundwater, was successful.

(c) 2018 Society of Chemical Industry

Keywords: sorption; bioremediation; mathematical modelling; optimization; water

\section{INTRODUCTION}

At the present time, human exposure to naturally high concentrations of arsenic (As) in groundwater is one of the most widespread environmental problems in many countries. ${ }^{1}$ This element is found as dissolved species, forming oxo-anions in natural waters. The predominant oxidation states are $\mathrm{As}(\mathrm{III}), \mathrm{As}(\mathrm{V})$ and, less frequently, $\mathrm{As}(0)$ and $\mathrm{As}(-\mathrm{III})$. The chemical speciation depends on the $\mathrm{pH}$ values of groundwater $(\mathrm{pH} 6.5-8.5){ }^{2}$ It can be present in inorganic and organic forms, with the former, in general, being the most toxic for people. ${ }^{3}$ The World Health Organization (WHO) recommends $0.01 \mathrm{mg} \mathrm{L}^{-1}$ as the maximum allowed As level for human and agriculture use, in order to reduce the negative impacts of this metalloid on human health. Although in Argentina the allowed value for drinking water ${ }^{4}$ is $0.05 \mathrm{mgAs} \mathrm{L}^{-1}$, elevated As concentrations are found in several states, such as Santa Fe, Córdoba and Chaco. The western region of Santa Fe State and Córdoba city, have concentrations that exceed 0.1 and $0.5 \mathrm{mgAs} \mathrm{L}^{-1}$, respectively. Another relevant point to highlight is the variability of As concentrations reported in the groundwater as a consequence of several factors, such as the amount and frequency of rainfall. To take this issue into account, it is necessary to study a wide range of As concentrations. Additionally, the search of economic/effective methods for the determination and elimination of As in communities with few economic resources has resulted in the development of new As quantification/removal technologies. In recent years, a wide variety of As elimination systems have been applied to decrease the presence of As in drinking water, food and vegetables. Amongst these, sorption is considered one of the best alternatives for treatment of contaminated water because of its minimal sludge production, simplicity, low cost and high efficiency. ${ }^{5}$ Conventional sorbents for As removal such as activated carbon and alumina are being displaced by new low-cost biosorbents such as plant biomass, algae, fungi, bacteria, and the biopolymers chitin and chitosan. ${ }^{6-8}$ Chitosan is a natural cationic aminopolysaccharide obtained by deacetylation of chitin, and several studies have reported that this polymer has good efficiency as an As sorbent. ${ }^{9,10}$ The presence of a large number of amino groups with affinity for arsenate ions, makes their favourable interaction possible. Its nontoxicity, abundance in nature and biodegradability are the main characteristics that make chitosan suitable for removing As from aqueous solutions. ${ }^{11}$

The major objective of the present work was to obtain the maximum sorption of As in groundwater onto chitosan using fixed-bed columns, by optimizing operational parameters of the columns (bed height and volumetric flow-rate). In order to describe the

\footnotetext{
Correspondence to: JC González, Facultad de Ciencias Bioquímicas y Farmacéuticas, Universidad Nacional de Rosario, Suipacha 531, S2002LRK Rosario, Santa Fe, Argentina.E-mail:gonzalez@iquir-conicet.gov.ar

a Área Química General e Inorgánica, Departamento de Química-Física, Facultad de Ciencias Bioquímicas y Farmacéuticas, Universidad Nacional de Rosario, Rosario, Argentina
}

b Instituto de Química de Rosario-CONICET, Rosario, Argentina 
dynamics of the sorption process in a continuous treatment mode, experimental breakthrough curves were fitted with nonlinear equations deriving from Yoon-Nelson, Thomas and Modified Dose-Response models. The statistical method Response Surface Methodology (RSM) based on Central Composite Design (CCD) was developed. ${ }^{12}$ and ANOVA, data regression and graphical analysis were performed to analyse the results.

\section{MATERIALS AND METHODS}

Groundwater samples were obtained from Piamonte Town, located in Santa Fe, Argentina. The characterization of groundwater is presented in Table 1.

Phosphate concentration was determined using Johnson's reducer and a colour reagent, prepared as follows:

Johnson's reducer: $14.0 \%$ sodium metabisulfite $\left(\mathrm{Na}_{2} \mathrm{~S}_{2} \mathrm{O}_{5}\right), 1.4 \%$ sodium thiosulfate $\left(\mathrm{Na}_{2} \mathrm{~S}_{2} \mathrm{O}_{3}\right)$ and $10.0 \%$ sulfuric acid $\left(\mathrm{H}_{2} \mathrm{SO}_{4}\right)$, in a volume ratio of 2:2:1.

Colour reagent: $11.0 \%$ ascorbic acid $\left(\mathrm{C}_{6} \mathrm{H}_{8} \mathrm{O}_{6}\right), 3.0 \%$ ammonium heptamolybdate $\left(\left(\mathrm{NH}_{4}\right)_{6} \mathrm{Mo}_{7} \mathrm{O}_{24} \cdot 4 \mathrm{H}_{2} \mathrm{O}\right), 1.1 \%$ antimony potassium tartrate $\left(\mathrm{C}_{4} \mathrm{H}_{4} \mathrm{~K}_{2} \mathrm{O}_{6} \mathrm{Sb} \cdot 1 / 2 \mathrm{H}_{2} \mathrm{O}\right)$ and $14.0 \%$ sulfuric acid $\left(\mathrm{H}_{2} \mathrm{SO}_{4}\right)$ in a volume ratio of 2:2:1:5.

Nitrate concentration was determined by a LAQUAtwin (Horiba Scientific, Japan) selective electrode, whereas a HANNA Conductivity Tester (DiST4, Romania) was used for conductivity/salinity measurement. The turbidity and colour of the samples were measured with a portable Habit $2100 \mathrm{Q} 01$ turbidimeter (Romania) and a HANNA water colour checker (HI 727, Romania), respectively.

In order to cover a possible range of As concentrations, water samples were supplemented by addition of sodium arsenate $\left(\mathrm{Na}_{2} \mathrm{HAsO}_{4} \cdot 7 \mathrm{H}_{2} \mathrm{O}\right)$ solution until they attained $1.0 \mathrm{mg} \mathrm{L}^{-1} \mathrm{As}(\mathrm{V})$. All of the reagents used for the current investigation were of analytical grade without any need for further purification.

\section{Analytical methods}

Arsenic concentrations in aqueous solutions were assessed by applying a bespoke modification of the As molybdenum blue method, $^{13}$ a simple and economical spectrophotometric procedure. In this the $\mathrm{As}(\mathrm{V})$ concentration was calculated from the absorbance difference between a reduced and a nonreduced sample. In the latter case, the absorbance would be given only by those interfering compounds which react with the colour reagent. Ten millilitre samples were divided in two parallel subsamples and acidified with $1.0 \% \mathrm{HCl}$ ( $25 \mathrm{~mL}$ final volume). One of the subsamples was treated with $2.5 \mathrm{~mL}$ of reducing reagent (Johnson's reducer), and the other was treated with $2.5 \mathrm{~mL}$ of Milli-Q water. After $30 \mathrm{~min}, 2.5 \mathrm{~mL}$ of colour reagent was added. Scheme 1 shows the steps followed in the determination of $\mathrm{As}(\mathrm{V})$.

After 30-40 min, absorbance at $890 \mathrm{~nm}$ was measured using a double beam spectrophotometer, with thermostatized cells and electronic temperature controller, Jasco V-550. Quartz cells of $10.0 \mathrm{~cm}$ optical path were used. As(V) concentration was calculated using the following equation [Eqn (1)]:

$$
[\text { As }(\mathrm{V})]=\frac{\left(A b s_{\text {untreated }}-A b s_{\text {reduced }}\right)}{\varepsilon b} f
$$

where $A b s$ is the absorbance of the sample, untreated or reduced, at $890 \mathrm{~nm}, \varepsilon$ is the molar absorptivity $\left(\mathrm{mol} \mathrm{L}^{-1} \mathrm{~cm}^{-1}\right), b$ is the optical path $(\mathrm{cm})$ and $f$ is the dilution factor.

It is pertinent to mention that this colorimetric method was used to determine the concentration of As present in groundwater of
Table 1. Characterization of groundwater (Piamonte Town)

\begin{tabular}{|lcc|} 
Components & $\begin{array}{c}\text { Pre-treatment } \\
\text { values }\end{array}$ & $\begin{array}{c}\text { Post-treatment } \\
\text { values }\end{array}$ \\
\hline $\mathrm{As}(\mathrm{V})\left(\mathrm{mg} \mathrm{L}^{-1}\right)$ & 0.035 & $<0.01$ \\
Turbidity $(\mathrm{NTU})$ & 0.01 & 0.01 \\
Nitrate $\left(\mathrm{mg} \mathrm{L}^{-1}\right)$ & 70 & 21 \\
Conductivity $\left(\mathrm{mS} \mathrm{cm}^{-1}\right)$ & 3.20 & 1.30 \\
Phosphate $\left(\mathrm{mg} \mathrm{L}^{-1}\right)$ & 0.02 & 0.01 \\
Salinity $\left(\mathrm{mg} \mathrm{L}^{-1}\right)$ & 2070 & 820 \\
\hline Initial groundwater $\mathrm{pH}=8.45$. & & \\
\hline
\end{tabular}

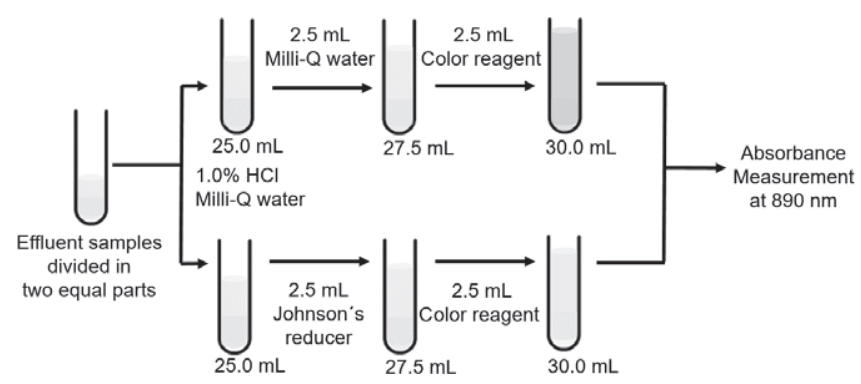

Scheme 1. Determination of $A s(V)$ concentration.

several Argentina cities as part of an interlaboratory program, and delivered comparable results to those obtained by more sophisticated and expensive methods [Atomic Absorption Spectrometry with Hydride Generation, graphite-furnace Atomic Absorption Spectrometry (SAA) and silver diethyldithiocarbamate].

Limit of detection (LD) and limit of quantification (LQ) were 0.0048 and $0.014 \mathrm{mg} \mathrm{L}^{-1}$, respectively. The $\mathrm{LQ}$ value was lower than the corresponding legislated number $\left(0.050 \mathrm{mg} \mathrm{L}^{-1}\right)$. The molar absorptivity $(\varepsilon)$ obtained in the experimental linear range (0.0050-0.50 $\left.\mathrm{mg} \mathrm{L}^{-1}\right)$ was $19100 \mathrm{M}^{-1} \mathrm{~cm}^{-1}$. The use of a cuvette with an optical path of $10.0 \mathrm{~cm}$ allowed increase in the sensitivity of this method. In this spectrophotometric method, species such as phosphate and silicate do not interfere in the determination of $\operatorname{As}(\mathrm{V})$.

\section{Chitosan characterization}

\section{pH zero-point charge determination}

The Mular-Roberts method ${ }^{14}$ was used to estimate the polymer $\mathrm{pH}$ zero-point charge $\left(\mathrm{pH}_{\mathrm{ZPC}}\right)$. One gram of chitosan was suspended in $50.0 \mathrm{~mL}$ of $0.01 \mathrm{~mol} \mathrm{~L}^{-1} \mathrm{NaNO}_{3}$, at different initial $\mathrm{pH}_{0}$ (5-8), and stirred $24 \mathrm{~h}(250 \mathrm{rpm})$ at room temperature. After the equilibrium time, the $\mathrm{pH}$ value (final $\mathrm{pH}$ ) was measured. The difference between initial and final $\mathrm{pH}, \Delta \mathrm{pH}$, was determined and plotted as a function of $\mathrm{pH}_{0}$. The $\mathrm{pH}_{\mathrm{ZPC}}$ value was indicated as the point where the resulting curve intersected the $x$-axis.

\section{Chitosan molecular weight $\left(\mathrm{M}_{\eta}\right)$}

The molecular weight estimation of chitosan polymer was carried out applying the capillary viscosity method. The technique was statistically validated according to linearity and repeatability criteria. Diluted chitosan solutions $\left(0.001-0.005 \mathrm{~g} \mathrm{~mL}^{-1}\right)$ were prepared dissolving chitosan in an aqueous mixture of $0.2 \mathrm{~mol} \mathrm{~L}^{-1}$ sodium chloride and $0.1 \mathrm{~mol} \mathrm{~L}^{-1}$ acetic acid. Relative viscosity $\left(\eta_{r}\right)$ and specific viscosity $\left(\eta_{s p}\right)$ were determined using a Cannon-Fenske 
(modified Ostwal, 75 series, VAT) capillary viscometer at $25^{\circ} \mathrm{C}$ and calculated according to Eqns (2) and (3), respectively:

$$
\begin{gathered}
\eta_{\mathrm{r}}=\frac{\eta}{\eta_{0}}=\frac{t}{t_{0}} \\
\eta_{\mathrm{sp}}=\frac{\eta-\eta_{0}}{\eta_{0}}=\frac{t-t_{0}}{t_{0}}
\end{gathered}
$$

where $t$ and $t_{0}$ are the draining time and, $\eta$ and $\eta_{0}$ are the viscosity, of diluted chitosan solutions and solvent, respectively. Huggins and Kramer demonstrated the empirical relationship between viscosity and concentration, ${ }^{15,16}$ which can be described by Eqns (4) and (5):

$$
\begin{gathered}
\eta_{\text {red }}=\frac{\eta_{\mathrm{sp}}}{\mathrm{C}}=[\eta]+k_{\mathrm{H}}[\eta]^{2} \mathrm{C} \\
\frac{\ln \eta_{\mathrm{r}}}{\mathrm{C}} \approx[\eta]+k_{\mathrm{K}}[\eta]^{2} \mathrm{C}
\end{gathered}
$$

where $k_{\mathrm{H}}$ and $k_{\mathrm{K}}$ are the Huggins and Kramer constants, respectively and $C$ is the solution concentration $\left(\mathrm{g} \mathrm{mL}^{-1}\right)$. The term $\eta_{s p} / C$ represents the reduced viscosity, $\eta_{\text {red }}$. The graphical representation of equations 4 and 5 , allows to obtain, by extrapolation at zero concentration, the intrinsic viscosity value, $[\eta]\left(\mathrm{mL} \mathrm{g}^{-1}\right)$. With this data, the viscosity average molecular weight $\left(M_{\eta}\right)$ of chitosan samples, can be calculated, applying the Mark-Houwink-Sakurada expression [Eqn (6)]:

$$
[\eta]=K\left(M_{\eta}\right)^{a}
$$

where $K=1.81 \times 10^{-3} \mathrm{~mL} \mathrm{~g}^{-1}$ and $a=0.93 .{ }^{17}$

\section{Deacetylation degree percentage (DDA)}

Chitosan deacetylation degree (DDA) was performed by ${ }^{1} \mathrm{H}$ nuclear magnetic resonance (NMR) based method. ${ }^{18}{ }^{1} \mathrm{H}$ NMR spectrum was collected in a Bruker Advance $300 \mathrm{MHz}$ Digital, with parameters NS $=64, \mathrm{SW}=12.98, \mathrm{O} 1 \mathrm{P}=5.5$ and $T=70^{\circ} \mathrm{C}$. A $5.0 \mathrm{~mm} \mathrm{NMR}$ test tube was filled with $5.0 \mathrm{mg}$ of chitosan and vacuum dried for $3.0 \mathrm{~h}$ at $50^{\circ} \mathrm{C}$. To dissolve the polymer, $0.5 \mathrm{~mL}$ of $2.0 \% \mathrm{DCl} / \mathrm{D}_{2} \mathrm{O}$ solution was added and the tube was kept at $70^{\circ} \mathrm{C}$.

Hirai and Lavertu reported a peak around $4.9 \mathrm{ppm}$, assigned to the $\mathrm{C} 1$ proton of the glucosamine unit in chitosan, and peaks at 3-4 ppm assigned to $\mathrm{C} 2-\mathrm{C} 6$ protons of glucosamine and $\mathrm{N}$-acetylglucosamine units. ${ }^{19,20}$ The $\mathrm{C} 1$ proton of the $\mathrm{N}$-acetylglucosamine unit appeared around $5.2 \mathrm{ppm}$, obtained from chitosan solution. The DDA\% was determined with Eqn (7), from the Hirai method. ${ }^{19}$

$$
\mathrm{DDA} \%=\left(1-\frac{\frac{1}{3} I \mathrm{CH}_{3}}{\frac{1}{6} I H_{2-6}}\right) \times 100
$$

where $I \mathrm{CH}_{3}$ is the integral intensity of resonance band due to $\mathrm{CH}_{3}$ residue of $\mathrm{N}$-acetylglucosamine and $\mathrm{IH}_{2-6}$ is the sum of integral intensities of $\mathrm{H}_{2}, \mathrm{H}_{3}, \mathrm{H}_{4}, \mathrm{H}_{5}$ and $\mathrm{H}_{6}$, protons. Replacing the experimental values of these terms in Eqn (7), resulted in Eqn (8).

$$
\mathrm{DDA} \%=\left(1-\frac{\frac{1}{3} \times 3}{\frac{1}{6} \times(22.1+3.1)}\right) \times 100
$$

\section{Continuous up-flow fixed-bed column sorption experiments}

Borosilicate glass columns of $10.0 \mathrm{~cm}$ length and $2.0 \mathrm{~cm}$ internal diameter were filled with different known amounts of commercial chitosan. Chitosan was previously hydrated in $250 \mathrm{~mL}$ of Milli-Q water at $\mathrm{pH} 4.5$ by addition of $1.7 \mathrm{~mol} \mathrm{~L}^{-1} \mathrm{H}_{2} \mathrm{SO}_{4}$ solution with constant agitation. The polymer, preserved between two polyurethane filters, was packed inside the column reaching the desired height and packing density. A solvent flow $\left(\mathrm{H}_{2} \mathrm{SO}_{4}, \mathrm{pH} 4.5\right)$ was applied in order to reach a flow rate and internal pressure constant to ensure complete hydration of chitosan, prevent appearance of air bubbles inside the column and keep the effluent $\mathrm{pH}$ constant over time.

Groundwater containing $1.0 \mathrm{mg} \mathrm{L}^{-1}$ of $\mathrm{As}(\mathrm{V})$ was pumped through the bed column at desired flow rates, with a peristaltic pump (Gilson Minipuls 3) in an up-flow mode, at $\mathrm{pH} 4.5$ and room temperature $\left(25^{\circ} \mathrm{C}\right)$. Samples were collected at different times to determinate the $\mathrm{As}(\mathrm{V})$ effluent concentration. The sorption process was continued until arsenic concentration in the samples reached the inlet concentration.

The $\mathrm{As}(\mathrm{V})$ sorption icapacity $\left(q_{t}\right)$ was determined from Eqn (9):

$$
q_{t}=\frac{m_{\mathrm{in}}-m_{\mathrm{out}}}{m_{\mathrm{s}}}=\frac{C_{0} V_{\mathrm{ef}}-Q \int_{0}^{t} C_{\mathrm{eff}}(t) \mathrm{dt}}{m_{\mathrm{s}}}
$$

In Eqn (9), $q_{t}$ represent the amount of $\mathrm{As}(\mathrm{V})$ uptake per unit mass of chitosan (sorption capacity) in $\mathrm{mg} \mathrm{g}^{-1}, m_{\text {in }}$ and $m_{\text {out }}$ are the total mass of $\mathrm{As}(\mathrm{V})$ input and output from the fixed-bed column $(\mathrm{mg}), m_{\mathrm{s}}$ is the dry mass of chitosan $(\mathrm{g}), C_{0}$ and $C_{\text {eff }}$ are the initial and effluent contaminant concentrations $\left(\mathrm{mg} \mathrm{L}^{-1}\right), V_{\text {ef }}$ is the total volume of treated contaminated water $(\mathrm{L}), Q$ is the volumetric flow-rate $\left(\mathrm{L} \mathrm{min}^{-1}\right)$ and $\int_{0}^{t} C_{\text {eff }}(t) d t$ represents the elution profile area $(\mathrm{mg})$. Integration limits, 0 and $t$, are the times associated to 0 and $0.95 C: C_{0}$ ratios, respectively.

The As $(V)$ mass not retained $\left(m_{\text {out }}\right)$ was calculated by integrating the column elusion profile and multiplying by the volumetric flow rate. The amount of arsenic ions entering through the column $\left(m_{\mathrm{in}}\right)$ can be calculated with Eqn (10):

$$
m_{\text {in }}=\frac{C_{0} Q t_{\mathrm{e}}}{1000}
$$

where $t_{\mathrm{e}}(\mathrm{min})$ is the column saturation time when $\mathrm{C}: \mathrm{C}_{0}=0.95$. Finally, $\mathrm{As}(\mathrm{V})$ removal percentage $(\% R)$ can be obtained from $m_{\text {in }}$ and $m_{\text {out }}$, through Eqn (11):

$$
\% R=\frac{m_{\text {in }}-m_{\text {out }}}{m_{\text {in }}} \times 100
$$

\section{Experimental column data modelling}

Several mathematical models describe the dynamics of the sorption process using fixed-bed columns. They help to analyse and explain the experimental data and predict changes due to different operational conditions.

\section{Thomas model}

The Thomas equation is one of the most frequently applied models to represent the sorption process performance in continuous systems. ${ }^{21}$ Column data might be used to calculate: the solid phase concentration of sorbate per sorbent unit $\left(q_{\mathrm{TH}}\right)$ and the minimum height of the bed $\left(L_{\mathrm{min}}\right)$ necessary to acquire a measurable breakthrough time, $t_{\mathrm{b}}$ (when the $C: C_{0}$ ratio is 0.05 ). 
This model assumes that: (i) radial and axial dispersions in the fixed-bed column are absent; (ii) sorption is described by a pseudo-second-order kinetics, reduced to a Langmuir isotherm at equilibrium; (iii) dead volume is not significant; (iv) the sorption process is carried out under isobaric and isothermal conditions; and $(\mathrm{v})$ properties of the solid and liquid phases remain constant. A mathematical expression of this model is presented in Eqn (12):

$$
\frac{C}{C_{0}}=\frac{1}{1+\mathrm{e}^{\frac{k_{\mathrm{TH}} q_{\mathrm{TH} \rho \mathrm{p}} A L}{\mathrm{Q}}}-k_{\mathrm{TH}} C_{0} t}
$$

where $k_{\mathrm{TH}}$ is the Thomas rate constant $\left(\mathrm{m}^{3} \mathrm{~mol}^{-1} \mathrm{~min}^{-1}\right), A$ is the cross-sectional area of the column $\left(\mathrm{m}^{2}\right), L$ is the height of the column bed $(\mathrm{m}), t$ is the sample acquisition time (min) and $\rho_{\mathrm{p}}$ is the packing density $\left(\mathrm{kg} \mathrm{m}^{-3}\right)$.

\section{Yoon-Nelson model}

Yoon and Nelson developed a simple model aimed at gas or vapour adsorption on activated carbon. ${ }^{22}$ This model does not require data regarding the physical properties and characteristics of sorbate, being less complex than other models. The probability of sorbate breakthrough on a sorbent is specified in Eqn (13).

$$
\frac{C_{0}}{C}=\frac{1}{1+\mathrm{e}^{k_{Y N}(\tau-t)}}
$$

In Eqn (13), $K_{Y N}$ is Yoon-Nelson's proportionality constant $\left(\mathrm{min}^{-1}\right)$ and $\tau$ is the time when output concentration equals to half of the input concentration. It is possible to calculate $q_{\mathrm{YN}}\left(\mathrm{mg} \mathrm{g}^{-1}\right)$ if the next equation [Eqn (14)] is applied:

$$
q_{\mathrm{YN}}=\frac{0.5 C_{0} Q 2 \tau}{m_{\mathrm{s}}}
$$

\section{Modified Dose-Response model}

This model was developed for describing different types of pharmacology processes but is now also used to analyse column sorption processes. $^{23}$ The Modified Dose-Response model can be defined by Eqn (15):

$$
\frac{C}{C_{0}}=1-\frac{1}{1+\left(\frac{C_{0} Q t}{q_{D R} m_{s}}\right)^{a}}
$$

where $a$ is the model constant.

The fitting error resulting from use of the Thomas model is minimized when Modified Dose-Response is applied, especially for elusion profiles with short and long breakthrough times. In Eqns (12)-(15) the terms $Q, C, C_{0}$ and $m_{\mathrm{s}}$ have the same meaning as previously defined in Eqns (9)-(11). Additionally, $q_{\mathrm{TH}}, q_{\mathrm{YN}}$ and $q_{\mathrm{DR}}$ are the maximum concentrations of solute sorbed on the solid phase $\left(\mathrm{mg} \mathrm{g}^{-1}\right)$ for Thomas, Yoon-Nelson and Modified Dose-Response models, respectively.

\section{Optimization of $\mathbf{A s}(\mathbf{V})$ adsorption on chitosan}

The response surface methodology (RSM) is well-defined as a set of mathematical techniques and advantageous statistics, used to model and analyse the response of interest, which is influenced by numerous variables.

For $\mathrm{As}(\mathrm{V})$ removal optimization, a rotable central composite design (CCD) was selected after preliminary tests. A 13 experiments $C C D$ came from the compositional arrangement
Table 2. Coded levels for independent factors used in the experimental design

\begin{tabular}{lcrrrrr|} 
& & \multicolumn{5}{c|}{ Coded levels } \\
\cline { 3 - 7 } Factors & Symbol & $-\alpha$ & -1 & 0 & 1 & $+\alpha$ \\
\hline Flow rate $\left(Q, \mathrm{~mL} \mathrm{~min}^{-1}\right)$ & $X_{1}$ & 3.0 & 3.5 & 4.8 & 6.0 & 6.6 \\
Column height $(h, \mathrm{~cm})$ & $X_{2}$ & 5.0 & 7.0 & 10.0 & 13.0 & 15.0 \\
\hline
\end{tabular}

$2^{k}+2 k+n$, with two factors $(k=2)$ and five central points $(n=5)$. Design Expert (v7.0, USA) was used for data analysis. Table 2 presents the range and levels of independent variables (column bed height and volumetric flow rate).

In order to study the $\mathrm{As}(\mathrm{V})$ percentage removal and recognize the most relevant terms of the model, a second-order polynomial equation [Eqn (16)], was applied:

$$
Y=\beta_{0}+\sum_{i=1}^{k} \beta_{i} X_{i}+\sum_{i=1}^{k} \beta_{\mathrm{ii}} X_{i}^{2}+\sum_{i, j=1}^{k} \beta_{\mathrm{ij}} X_{i} X_{j}+\varepsilon
$$

where $Y$ is the response, $\beta_{0}$ is the constant coefficient, $\beta_{i}$ and $\beta_{i i}$ are the linear and quadratic coefficients (respectively) of the independent factor $X_{i}, \beta_{i j}$ is the coefficient of interaction between the independent factors $X_{i}$ and $X_{j}$ and, finally, $\varepsilon$ represents the model error.

For the RSM, experimental conditions were $\mathrm{pH}=4.5$, packing density $=270 \mathrm{~kg} \mathrm{~m}^{-3}$ and $[\mathrm{As}(\mathrm{V})]_{0}=1.0 \mathrm{mg} \mathrm{L}^{-1}$, and evaluated factors were bed height, $h(3.0-6.6 \mathrm{~cm})$ and volumetric flow rate, $Q$ (5.0-15.0 $\mathrm{mL} \mathrm{min}^{-1}$ ).

In order to fit the response function to the experimental data, regression analysis was performed. The probability $P$-value, standard error of coefficient (SE coefficient) and $T$-value were applied to determine the significance of the regression coefficients for each parameter. The value $P$ is the smallest level of significance to reject the null hypothesis and determine which variables are statistically significant, SE is a measure of the variation in estimating the coefficient and $T$ is the ratio of the coefficients to the standard error. These effects are significant when their probability level is $5 \%(P<0.05)$. Usually, the higher and lower values of $T$ and $P$, respectively, the more significant are the corresponding coefficient terms. ${ }^{24} \mathrm{~A}$ positive value of the regression coefficient means an enhancing effect, whereas a negative sign indicates an opposed effect of the factor in the response.

ANOVA is the most reliable way to evaluate the quality of the adjusted model and it was used to verify the statistical significance of the ratio of mean square due to regression and mean square due to residual error ( $F$-value). The variation in the response can be explained by the regression model equation when a large $F$ is acquired. To decide whether $F$ is large enough to indicate statistical significance, an associated $P$ is used. If $P$ for a large $F$ is lower than 0.05 , it means $95 \%$ confidence, and the model is statistically significant. ${ }^{25}$ To probe the relationship between three and two variables, 3D Surface and Contour graphs can be applied. ${ }^{26}$ Both kinds of graph can be helpful to identify: (i) optimum settings and (ii) the best settings for each response.

\section{RESULTS AND DISCUSSION}

\section{Chitosan characterization}

For chitosan $\mathrm{pH}_{\mathrm{ZPC}}$ determination, it is important to know the $\mathrm{pH}$ value at which the polymer surface does not present charge. In 


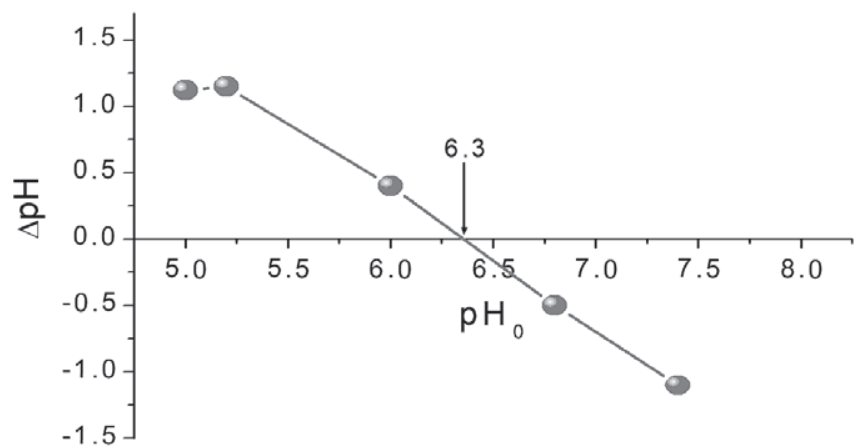

Figure 1. The $\mathrm{pH}$ of zero-point charge of chitosan polymer. Sorbent dose $20 \mathrm{~g} \mathrm{~L}^{-1}, \mathrm{NaNO}_{3} 0.01 \mathrm{~mol} \mathrm{~L}^{-1}, T=25^{\circ} \mathrm{C}, 24 \mathrm{~h}$ equilibrium time.

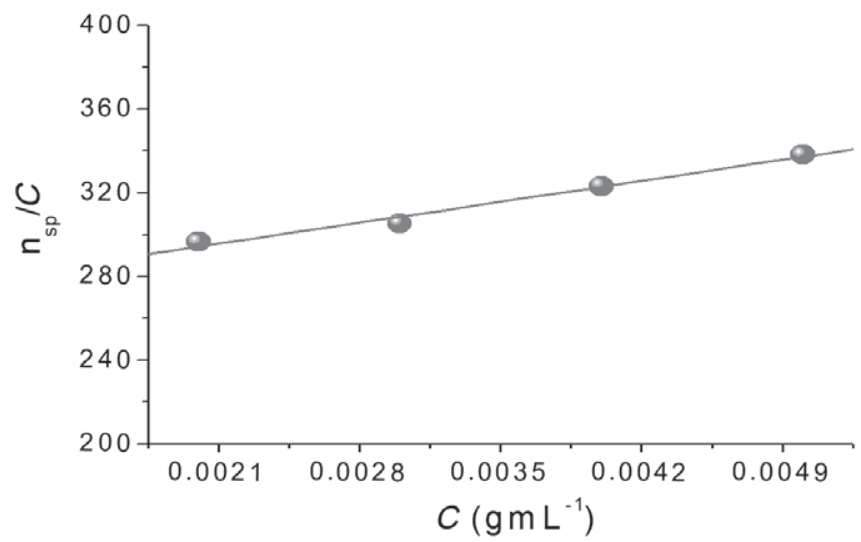

Figure 2. Graphical representation of experimental data fitting with the Huggins' function.

this study, the chitosan $\mathrm{pH}_{\mathrm{ZPC}}$ obtained was 6.3, a value similar to data in the literature (Fig. 1). ${ }^{27}$ At pH lower than 6.3 the amino groups are protonated, and therefore the polymer surface area is positively charged, showing a great tendency to adsorb anions. ${ }^{28}$ Arsenic acid predominates only at extremely low $\mathrm{pH}$, a rare situation in groundwater. At pH 3.0-6.9, $\mathrm{As}(\mathrm{V})$ is found as $\mathrm{H}_{2} \mathrm{AsO}_{4}{ }^{-}$. This means there is a favourable interaction between $\mathrm{NH}_{3}{ }^{+}$groups in chitosan and $\mathrm{H}_{2} \mathrm{AsO}_{4}{ }^{-}$species under $\mathrm{pH}$ 6.3.

In order to determine the chitosan molar mass, a viscosimetry technique was used. A decrease in the reduced viscosity could be observed as the polymer concentration decreased (Fig. 2). This result indicated that, under our experimental conditions, it was appropriated to use the Huggins expression. The graph derived from the Kramer equation is presented in Fig. 3. According to

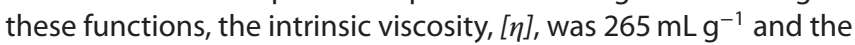
chitosan average viscous molecular mass was $350 \pm 10 \mathrm{kDa}$.

According to the literature, ${ }^{18} \mathrm{H}^{1}$ NMR has been found to be the most reliable method for determining DDA\%. The result thus obtained was $76.2 \%$.

\section{Bed height and volumetric flow-rate effects: experimental} column data modelling

The breakthrough curves for $\mathrm{As}(\mathrm{V})$ sorption on chitosan, using bed height columns of 3.0 and $6.6 \mathrm{~cm}$ (2.30 and $5.10 \mathrm{~g}$, respectively), at $10.0 \mathrm{~mL} \mathrm{~min}{ }^{-1}$ constant volumetric flow-rate, are presented in Fig. 4. It is evident that the breakthrough time $\left(t_{\mathrm{b}}\right)$ and the saturation time $\left(t_{\mathrm{e}}\right)$ showed an increment with a higher bed height. Saturation time of the column was high due to the increment in the

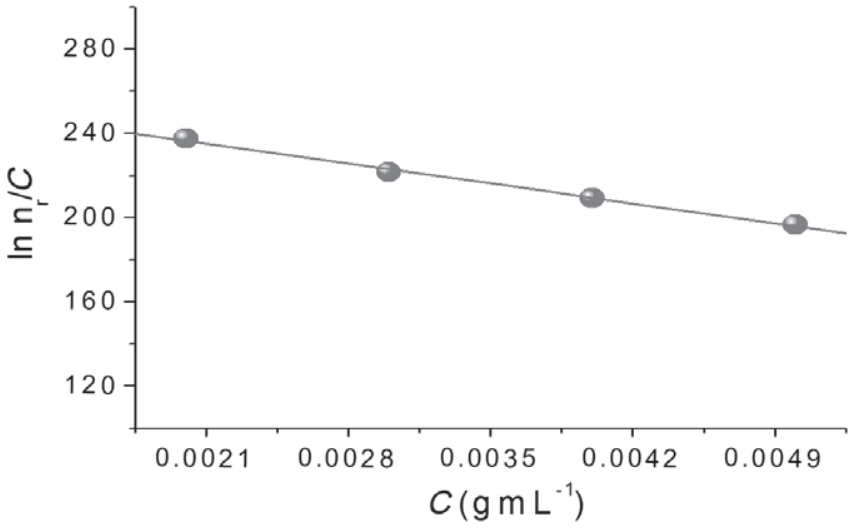

Figure 3. Graphical representation of experimental data fitting of Kramer's function.

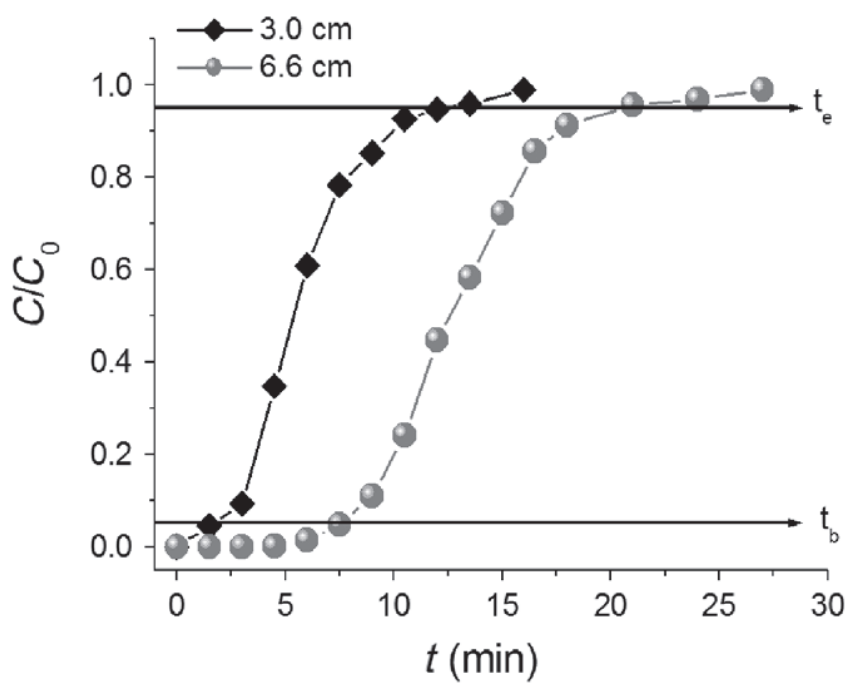

Figure 4. Breakthrough curves for different bed heights. Experimental parameters: $[\mathrm{As}(\mathrm{V})]_{0}=1.0 \mathrm{mg} \mathrm{L}^{-1}, Q=10.0 \mathrm{~mL} \mathrm{~min}^{-1}, \quad \mathrm{pH}=4.5$, $\rho=270 \mathrm{~kg} \mathrm{~m}^{-3}, T=25^{\circ} \mathrm{C}$.

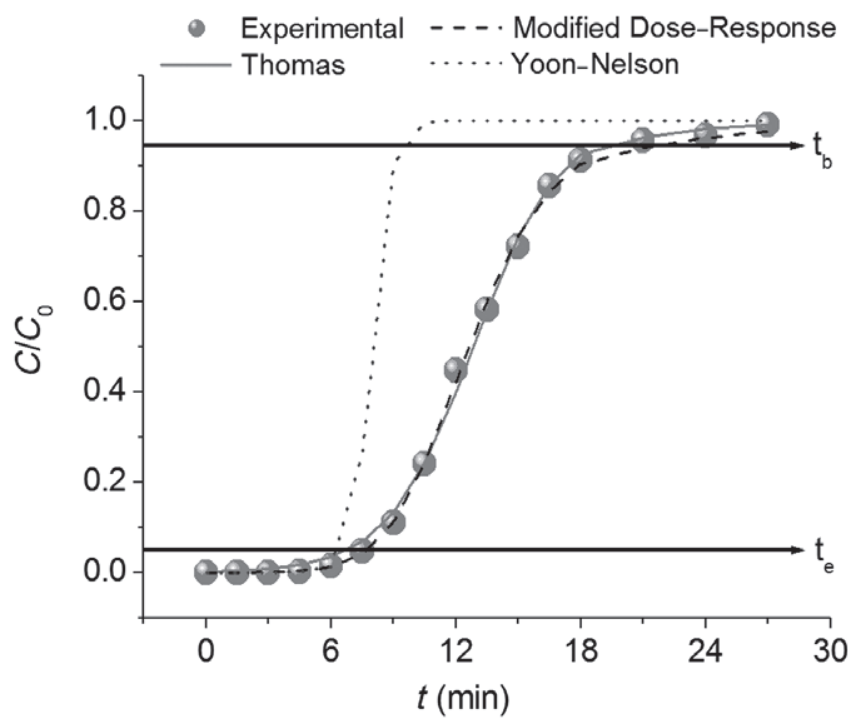

Figure 5. Elution profiles described by Thomas, Modified Dose-Response and Yoon-Nelson models. Experimental parameters: $[\mathrm{As}(\mathrm{V})]=1.0 \mathrm{mg} \mathrm{L}^{-1}$, $h=6.6 \mathrm{~cm}, Q=10 \mathrm{~mL} \mathrm{~min}^{-1}, \mathrm{pH}=4.5, \rho=270 \mathrm{~kg} \mathrm{~m}^{-3}, T=25^{\circ} \mathrm{C}$. 


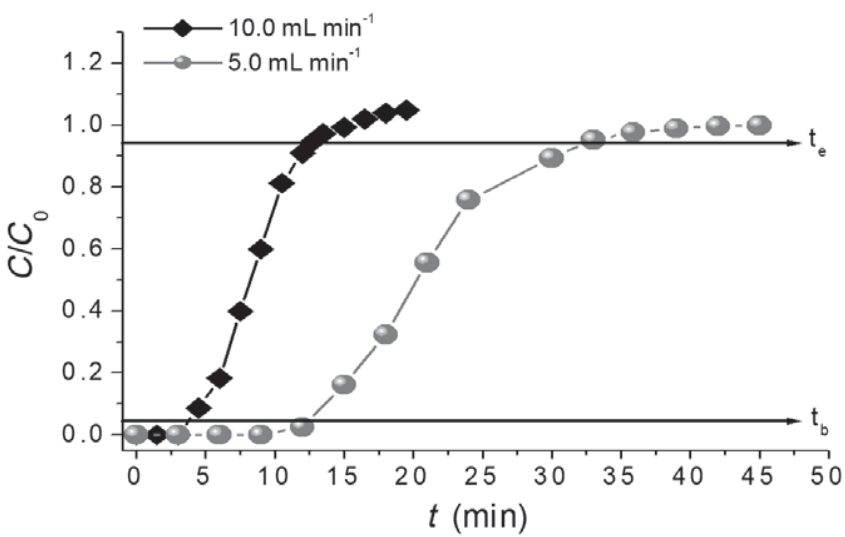

Figure 6. Breakthrough curves for different flow rates. Experimental parameters: $[\mathrm{As}(\mathrm{V})]=1.0 \mathrm{mg} \mathrm{L}^{-1}, h=4.8 \mathrm{~cm}, \mathrm{pH}=4.5, \rho=270 \mathrm{~kg} \mathrm{~m}^{-3}$, $T=25^{\circ} \mathrm{C}$.

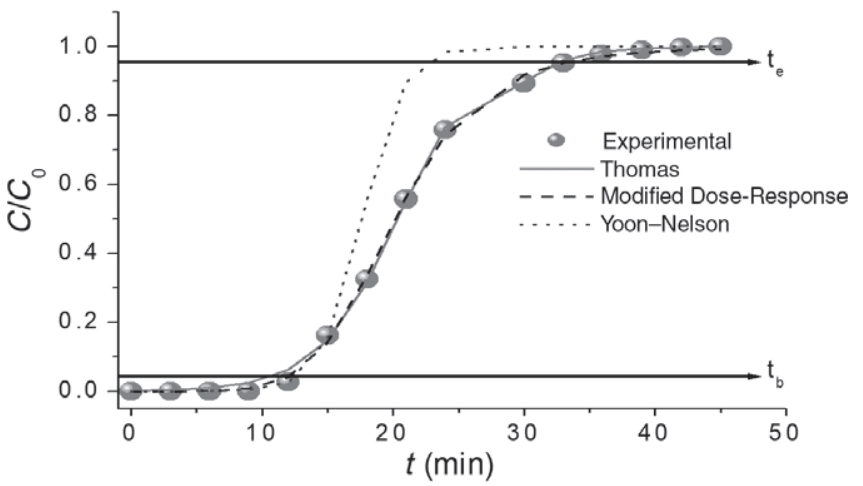

Figure 7. Elution profiles described by Thomas, Modified Dose-Response and Yoon Nelson models. Experimental parameters: $[\mathrm{As}(\mathrm{V})]=1.0 \mathrm{mg} \mathrm{L}^{-1}$, $h=4.80 \mathrm{~cm}, Q=5.0 \mathrm{~mL} \mathrm{~min}^{-1}, \mathrm{pH}=4.5, \rho=270 \mathrm{~kg} \mathrm{~m}^{-3}, T=25^{\circ} \mathrm{C}$.

quantity of active binding sites present in the biopolymer, allowing a greater retention and, therefore, a low effluent concentration of the pollutant. This behaviour also was observed by other authors. ${ }^{29}$

Experimental data were best described by Modified Dose-Response and Thomas models. The $R^{2}$ values of both models exhibited a good fit to the experimental data (Fig. 5), whereas the Yoon-Nelson model could not be used to fit these data.

Breakthrough curves at two values of volumetric flow (5.0 and $10.0 \mathrm{~mL} \mathrm{~min}{ }^{-1}$ ) with a constant sorbent bed height of $4.8 \mathrm{~cm}$
Table 4. Full factorial design for the independent variables with responses for $\mathrm{As}(\mathrm{V})$ removal

\begin{tabular}{rcccc|}
$\begin{array}{c}\text { Run } \\
\text { order }\end{array}$ & $\begin{array}{c}X_{1}: \\
\text { flow rate } \\
\left(\mathrm{mL} \mathrm{min}^{-1}\right)\end{array}$ & $\begin{array}{c}X_{2}: \\
\text { bed height } \\
(\mathrm{cm})\end{array}$ & $\begin{array}{c}\text { Response } \\
(\% \text { removal) } \\
\text { Experimental }\end{array}$ & Predicted \\
\hline 1 & 10.0 & 6.6 & 64.11 & 64.28 \\
2 & 15.0 & 4.8 & 50.02 & 48.11 \\
3 & 10.0 & 4.8 & 60.50 & 63.90 \\
4 & 5.0 & 4.8 & 55.12 & 57.18 \\
5 & 10.0 & 3.0 & 43.99 & 42.91 \\
6 & 13.0 & 6.0 & 55.87 & 56.86 \\
7 & 13.0 & 3.5 & 45.98 & 47.08 \\
8 & 10.0 & 4.8 & 63.25 & 63.90 \\
9 & 7.0 & 6.0 & 70.01 & 67.92 \\
10 & 10.0 & 4.8 & 64.22 & 63.90 \\
11 & 7.0 & 3.5 & 48.10 & 46.43 \\
12 & 10.0 & 4.8 & 65.05 & 63.90 \\
13 & 10.0 & 4.8 & 67.13 & 63.90 \\
\hline
\end{tabular}

(3.70 g) are shown in Fig. 6. A lower flow rate causes a longer residence time of the sorbate inside the column, favouring the sorption process and breakthrough occurs at longer times. This result is in agreement with an increase in treated water volume with a $C: C_{0}$ ratio $<0.05$. Modelling of one experimental elution curve with the suggested models is shown in Fig. 7. It can be concluded that, as was observed previously, Modified Dose-Response and Thomas models represent the experimental results better than the Yoon-Nelson model. Table 3 exhibits the parameters of the different mathematical models.

\section{Optimization for As(V) biosorption process}

A CCD method was applied in this study to find out the optimal conditions to remove $\mathrm{As}(\mathrm{V})$ from contaminated groundwater. A total of 13 experimental runs were performed to examine the combined effect of two different independent parameters (bed height and volumetric flow rate) on $\mathrm{As}(\mathrm{V})$ percentage removal. Table 4 presents the experimental design and results obtained. Interpretation of ANOVA was performed to evaluate the quality of the adjusted model. To investigate the factor effects, 3D Response Surface and Contour plots were employed.

The second-order model expression for the parameters studied in the optimization of the chitosan- $\mathrm{As}(\mathrm{V})$ sorption, can be

Table 3. Parameters for Thomas and Modified Dose-Response models

\begin{tabular}{|c|c|c|c|c|c|c|c|c|}
\hline \multirow{2}{*}{$\begin{array}{l}\text { Factor } \\
h^{\mathrm{a}}(\mathrm{cm})\end{array}$} & \multicolumn{4}{|c|}{ Thomas model } & \multicolumn{4}{|c|}{ Modified Dose-Response model } \\
\hline & $k_{\mathrm{TH}}\left(\mathrm{m}^{3} \mathrm{~mol}^{-1} \mathrm{~min}^{-1}\right)$ & $q_{\mathrm{TH}}\left(\mu \mathrm{g} \mathrm{g}^{-1}\right)$ & $R^{2}$ & $\chi^{2}$ & $a$ & $q_{\mathrm{DR}}\left(\mu \mathrm{g} \mathrm{g}^{-1}\right)$ & $R^{2}$ & $\chi^{2}$ \\
\hline 3.0 & 61.7 & 37.3 & 0.9981 & 0.0004 & 6.9 & 41.0 & 0.9990 & 0.0001 \\
\hline 6.6 & 56.2 & 14.4 & 0.9974 & 0.0004 & 5.5 & 18.5 & 0.9984 & 0.0002 \\
\hline \multicolumn{9}{|c|}{$\mathrm{Q}^{\mathrm{b}}\left(\mathrm{mL} \min ^{-1}\right)$} \\
\hline 5.0 & 81.7 & 9.5 & 0.9991 & 0.0002 & 7.6 & 10.1 & 0.9992 & 0.0002 \\
\hline 10.0 & 65.0 & 16.7 & 0.9992 & 0.0002 & 5.4 & 21.8 & 0.9998 & 0.0006 \\
\hline
\end{tabular}




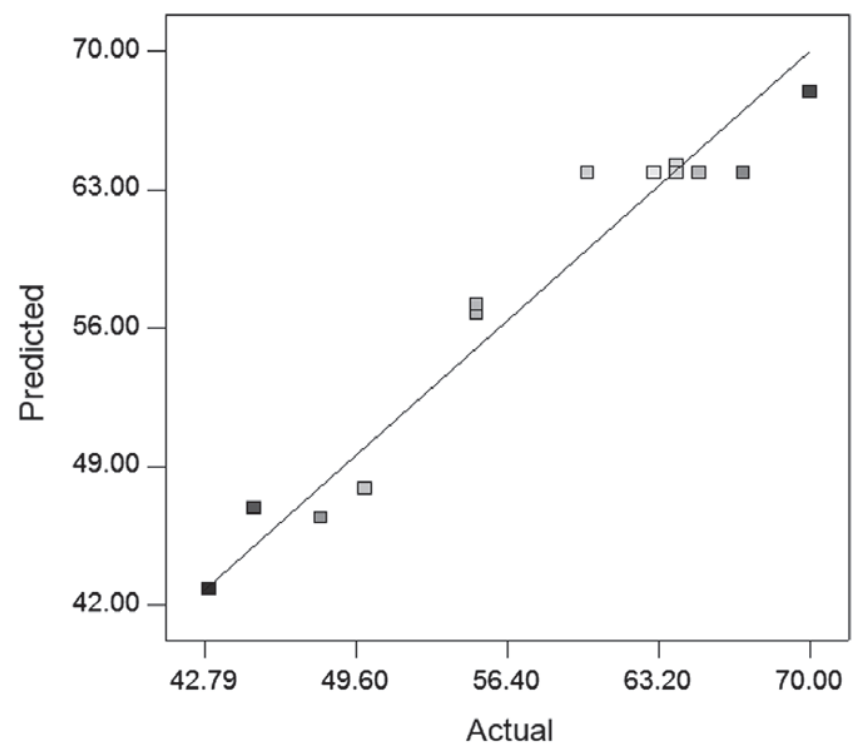

Figure 8. Comparison between actual and predicted values of RSM for $\mathrm{As}(\mathrm{V})$ biosorption.

expressed in coded units by Eqn (17):

$$
\% R=63.50-3.17 X_{1}+7.76 X_{2}-5.64 X_{1}^{2}-4.87 X_{2}^{2}-3.42 X_{1} X_{2}
$$

The regression model obtained for $\mathrm{As}(\mathrm{V})$ removal was appropriated $\left(R^{2}=0.9477\right)$ : this means the model explains $94.77 \%$ of the response variability. ${ }^{30}$ The predicted $R^{2}(0.7506)$ is in reasonable agreement with the adjusted $R^{2}(0.9104)$, which rules out the presence of outliers. Figure 8 , shows the relationship between actual and predicted values, and the relative goodness-of-fit of the model. Besides, adequate precision resulted equal to 13.90 , which implies the entire response surface can be navigated. No outliers

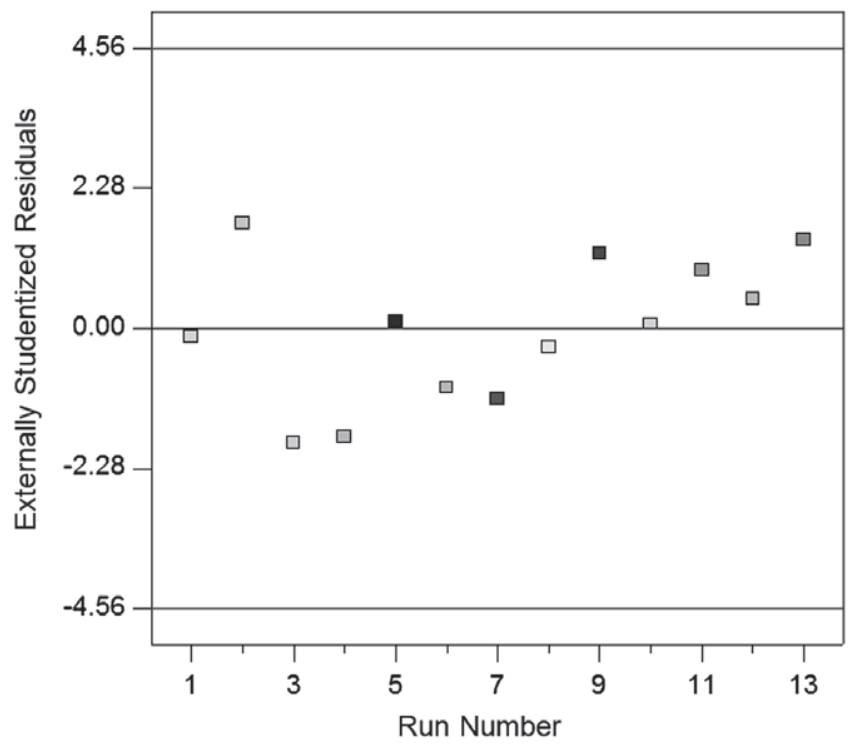

Figure 9. Plot of studentized residuals versus experimental run number.

were observed for a significance level of 0.05 and residuals were scattered randomly around \pm 4.56 (Fig. 9).

Table 5 presents ANOVA results. The observed $F$-value was 25.38 , suggesting that the model was significant, with $P<0.05$. Therefore, the null hypothesis, which indicates that none of the independent variables (bed height and volumetric flow rate) explains the variation of the dependent variable (\% removal of As), was rejected. The nonsignificant lack-of-fit value $(F=1.14)$ showed that the developed model was valid. ${ }^{31}$ However, the linear effect of selected factors $h$ and $Q$ was statistically significant $(P<0.05)$. The bed height showed a stronger influence than the flow rate $(P<0.0001$ and $T=8.43)$, which also could be deduced from the coefficient factors in Eqn (17). The percentage

\begin{tabular}{|c|c|c|c|c|c|}
\hline Term & Coefficients & Standard error & \multicolumn{2}{|c|}{$T$-value } & $P$-value \\
\hline Intercept & 63.50 & 1.18 & \multicolumn{2}{|c|}{53.81} & $<0.0001$ \\
\hline$x_{1}$ & -3.17 & 1.02 & \multicolumn{2}{|c|}{-3.11} & 0.0169 \\
\hline$x_{2}$ & 7.76 & 0.92 & \multicolumn{2}{|c|}{8.43} & $<0.0001$ \\
\hline$x_{1} x_{2}$ & -3.42 & 1.55 & \multicolumn{2}{|c|}{-2.21} & 0.0437 \\
\hline$x_{1}^{2}$ & -5.64 & 1.07 & \multicolumn{2}{|c|}{-5.27} & 0.0012 \\
\hline$x_{2}^{2}$ & -4.87 & 0.97 & \multicolumn{2}{|c|}{-5.02} & 0.0016 \\
\hline \multicolumn{6}{|c|}{ ANOVA } \\
\hline Source & Sum of squares & Degrees of freedom & Mean square & $F$-value & $P$-value \\
\hline Model & 899.46 & 5 & 179.89 & 25.38 & 0.0002 \\
\hline Residual & 49.62 & 7 & 7.09 & & \\
\hline Lack-of-fit & 22.82 & 3 & 7.61 & 1.14 & 0.4355 \\
\hline Pure Error & 26.80 & 4 & 6.70 & & \\
\hline Cor Total & 949.08 & 12 & & & \\
\hline Standard deviation & 2.66 & $R^{2}$ & 0.9477 & & \\
\hline Mean & 57.62 & $\operatorname{Adj} R^{2}$ & 0.9104 & & \\
\hline CV (\%) & 4.62 & Pred $R^{2}$ & 0.7506 & & \\
\hline PRESS & 236.74 & Adeq Precision & 13.897 & & \\
\hline
\end{tabular}




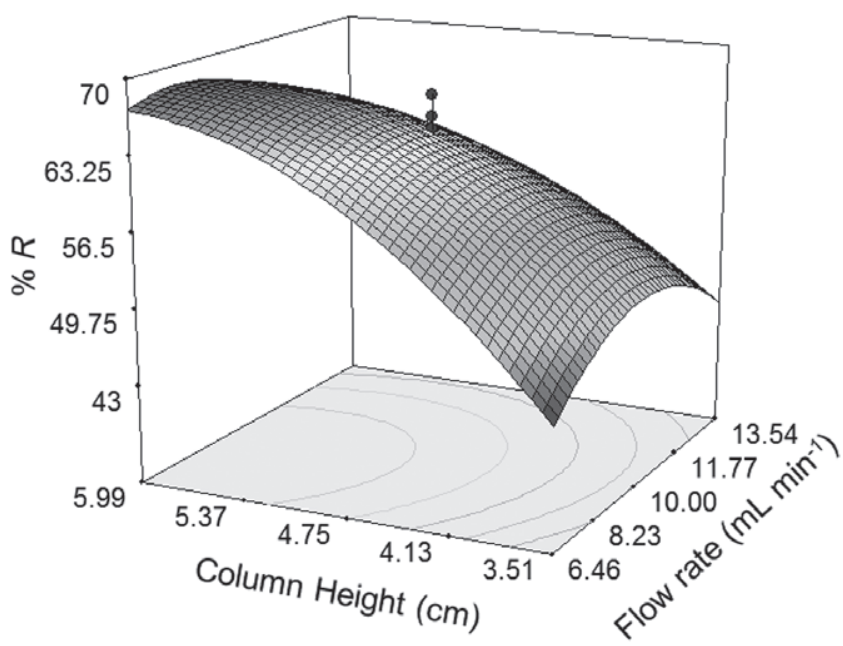

Figure 10. 3D Response Surface plot for $\% A s(V)$ removal for combined effect of bed height and flow rate.

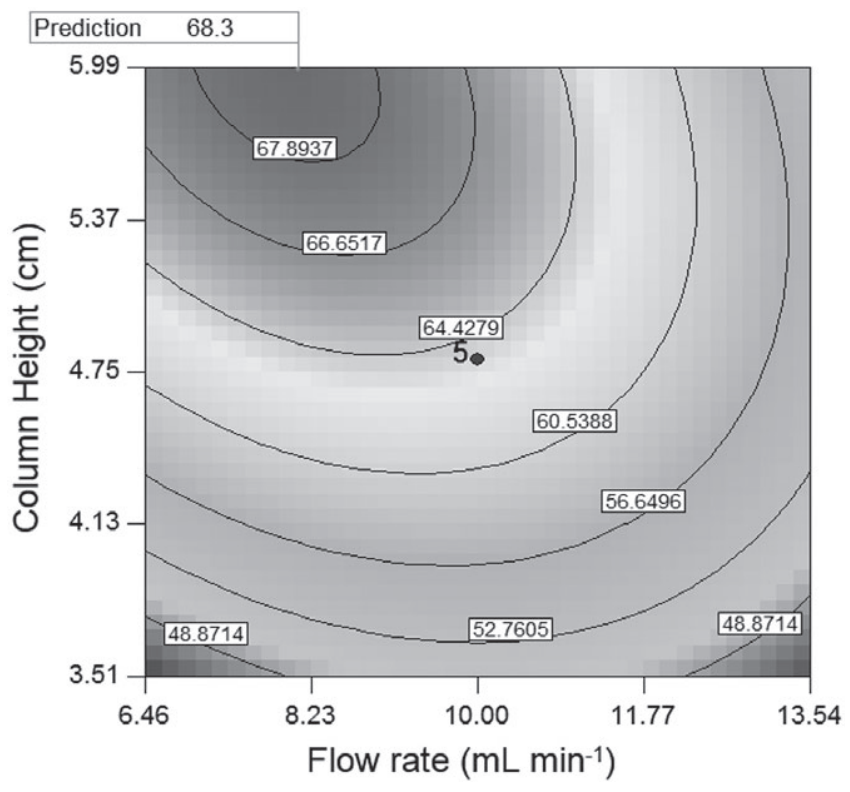

Figure 11. Contour plot of $\%$ As removal efficiency representing volumetric flow rate and column bed height.

removal of As increased with a bed height increment in the range studied.

Quadratic effect and two-factor interactions were significant, indicating that there was a curve relationship between factors and response.

\section{Quantitative effects of the factors}

The combined effects of flow rate and bed column height on $\mathrm{As}(\mathrm{V})$ removal efficiency at constant $\mathrm{As}(\mathrm{V})$ concentration $\left(1.0 \mathrm{mg} \mathrm{L}^{-1}\right)$, $\mathrm{pH}$ (4.5) and packing density $\left(270 \mathrm{~kg} \mathrm{~m}^{-3}\right)$, is depicted in 3D view and Contour Response Surface plots. Figure 10 visualizes the clear increase in $\mathrm{As}(\mathrm{V})$ removal resulting from increasing the bed height and decreasing the flow rate. In this way, the capability to maximize the arsenic removal applying a continuous sorption process, within the factor levels studied in this work, was clearly demonstrated. The curved contour lines in Fig. 11 show that there was a strong interaction between bed height and flow rate, reflected by the corresponding $P$-value. The optimal conditions for As adsorption from groundwater using chitosan as sorbent were: $5.9 \mathrm{~cm}$ bed column height and $7.8 \mathrm{~mL} \mathrm{~min}^{-1}$ volumetric flow-rate, being $68.3 \%$ the theoretical maximum $\mathrm{As}(\mathrm{V})$ removal. Under these conditions, three independent experiments for As sorption in up-flow fixed-bed column mode were conducted. The experimental value reached $(68.5 \pm 0.5 \%)$ was in agreement with the maximum predicted by the experimental design.

Chitosan at $\mathrm{pH} 4.5$ works like a cation exchanger because its protonated $\mathrm{NH}_{2}$ groups can interact with arsenate ions; additionally, there could be retention of other anions present in groundwater. The reduction in nitrate and phosphate concentrations, and in conductivity/salinity in the effluent samples after short sorption treatment times were $70 \%, 50 \%$ and $60 \%$ respectively, supporting this ionic interaction. At long sorption treatment times, no reduction of these compounds was evident, and therefore it could be assumed that the polymer binding sites are saturated with these ions.

Recovery of As from columns was performed with $0.05 \mathrm{~mol} \mathrm{~L}^{-1}$ $\mathrm{H}_{2} \mathrm{SO}_{4}$ solution at $0.1 \mathrm{~mL} \mathrm{~min}^{-1}$ flow rate. It was observed that the percentage of $\mathrm{As}(\mathrm{V})$ desorption was $92 \%$ in agreement with a weakly bonded $\mathrm{As}(\mathrm{V}) /$ chitosan active sites. The $\mathrm{As}(\mathrm{V})$ removal percentage during the second cycle sorption was $88 \%$, indicating no strong changes in the interaction biopolymer/As(V). Therefore, the polymer maintained its structural stability after the first cycle of regeneration.

\section{CONCLUSIONS}

This study was focused on: (i) $\mathrm{As}(\mathrm{V})$ detection and quantification by means of an optimized, green, cheap and accessible spectrophotometric method with a suitable sensitivity for use in groundwater (a complex matrix); and (ii) optimization of $\mathrm{As}(\mathrm{V})$ sorption present in groundwater onto chitosan, a natural, biodegradable biopolymer, in a continuous column mode by the Response Surface Methodology. It was found that $\mathrm{As}(\mathrm{V})$ uptake increased with increased bed height, but decreased with the flow rate. It was found that $A s(V)$ uptake increased with an increment of the bed height, but decreased with a flow rate increment. These results demonstrate the possibility of employing chitosan as a sorbent for $\mathrm{As}(\mathrm{V})$ removal in a continuous process and the usefulness of statistical models. There was an additional finding that (iii) nitrate, phosphate and salinity/conductivity reduced in the effluent under short sorption treatment times. Consequently, the effluent water quality suggests that the treated groundwater could be used not only for household purposes, but also as irrigation water without affecting sensitive agricultural crops.

\section{ACKNOWLEDGEMENTS}

We thank the National Research Council of Argentina (CONICET) PIP 0037, National Agency of Scientific and Technological Promotion (ANPCyT) PICT 2016-1611, Santa Fe Province Agency of Science, Technology and Innovation ASACTEI N AC 2015-0005, $\mathrm{N}^{\circ}$ resol 118-16 project number 2010-174-16 and National University of Rosario (UNR) BIO425 for financial support.

\section{REFERENCES}

1 Singh R, Singh S, Parihar P, Singh V and Prasad S, Arsenic contamination, consequences and remediation techniques: a review. Ecotoxicol Environ Saf 112:247-270 (2015). 
2 Shankar S, Shanker U and Shikha, Arsenic contamination of groundwater: a review of sources, prevalence, health risks, and strategies for mitigation. Sci World J 2014:1 - 18 (2014).

3 Carlin DJ, Naujokas MF, Bradham KD, Cowden J, Heacock M, Henry HF et al., Arsenic and environmental health: state of the science and future research opportunities. Environ Health Perspect 124:890-899 (2016).

4 COHIFE, Federal Water Council. [Online]. Available: http://www. cohife .org [5 September 2018].

5 Volesky B, Sorption and Biosorption. BV Sorbex Inc, McGill University, Canada (2003).

6 Saqiba A, Waseema A, Khanb A, Mahmoodc Q, Khana A, Habibd A et al., Arsenic bioremediation by low cost materials derived from Blue Pine (Pinus wallichiana) and Walnut (Juglans regia). Ecol Eng 51:88-94 (2013).

7 Tuzena M, Sari A, Mendila D and Uluozlu OD, Characterization of biosorption process of As(III) on green algae Ulothrix cylindricum. $J$ Hazard Mater 165:566-572 (2009).

8 Wang $\mathrm{S}$ and Zhao $\mathrm{X}$, On the potential of biological treatment for arsenic contaminated soils and groundwater. J Environ Manage 90:2367-2376 (2009).

9 Escudero-Oñate $C$ and Martínez-Francés $\mathrm{E}$, A review of chitosan-based materials for the removal of organic pollution from water and bioaugmentation. Chapter 4, in Chitin-Chitosan - Myriad Functionalities in Science and Technology, ed. by Rajendra D. IntechOpen Limited, RTM Nagpur University, London, pp. 71-87 (2018).

10 Kwok K, Koong L, Chen G and McKay G, Mechanism of arsenic removal using chitosan and nanochitosan. J Colloid Interface Sci 4:1-10 (2014).

11 Pontoni $L$ and Fabbricin M, Use of chitosan and chitosan-derivatives to remove arsenic from aqueous solutions: a mini review. Carbohydr Res 356:86-92 (2012).

12 Witek-Krowiak A, Chojnacka K, Podstawczyk D, Dawiec A and Pokomeda K, Application of response surface methodology and artificial neural network methods in modelling and optimization of biosorption process. Bioresour Technol 160:150-160 (2014).

13 Shan $\mathrm{Hu} \mathrm{H}$, Jinsuo L and Chuanyong J, A novel colorimetric method for field arsenic speciation analysis. J Environ Sci 24:1341-1346 (2012).

14 Mular A and Roberts RB, A simplified method to determine isoelectric point of oxides. Trans Can Min Metall 69:438 (1966).

15 Huggins ML, The viscosity of dilute solutions of long-chain molecules. Dependence on concentration. J Am Chem Soc 64:2716-2718 (1942).

16 Kramer EO, Molecular weight of celluloses and cellulose derivates. J Ind Eng Chem 30:1200-1203 (1938).

17 Roberts GAF and Domszy JG, Determination of the viscosimetric constants for chitosan. Int J Biol Macromol 4:374-377 (1982).
18 Abdou E, Nagy K and Elsabee M, Extraction and characterization of chitin and chitosan from local sources. Bioresour Technol 99:1359-1367 (2008).

19 Hirai $\mathrm{H}$, Odani $\mathrm{H}$ and Nakajima A, Determination of degree of deacetylation of chitosan by 1H NMR spectroscopy. Polym Bull 26:87-94 (1991).

20 Lavertu M, Xia Z, Serreqi AN, Berrada M, Rodriques A, Wang AD et al., $A$ validated $1 \mathrm{H}$ NMR method for the determination of the degree of deacetylation of chitosan. J Pharm Biomed Anal 32:1149-1158 (2003).

21 Thomas $\mathrm{H}$, Heterogeneous ion exchange in a flowing system. J Am Chem Soc 66:1664-1666 (1944).

22 Yoon $\mathrm{YH}$ and Nelson $\mathrm{JH}$, Application of gas adsorption kinetics theoretical model for respirator cartridge service life. Am Ind Hyg Assoc J 45:509-516 (1984).

23 Yan G, Viraraghavan $T$ and Chen $M, A$ new model for heavy metal removal in a biosorption column. Adsorpt Sci Technol 19:25-43 (2001).

24 Del Angel Sanchez MT, García-Alamilla P, Lagunes-Gálvez LM, García-Alamilla R and Cabrera Culebro EG, Aplicación de metodología de superficie de respuesta para la degradación de naranja de metilo con tio2 sol-gel sulfatado. Rev Int Contam Ambiet 31:99-106 (2015).

25 Ranjan D and Hasan SH, Parametric optimization of selenite and selenate biosorption using wheat bran in batch and continuous mode. J Chem Eng Data 55:4808-4816 (2010).

26 Xu M, Yin P, Liu X, Tang Q, Qu R and Xu Q, Utilization of rice husks modified by organomultiphosphonic acids as low-cost biosorbents for enhanced adsorption of heavy metal ions. Bioresour Technol 149:420-424 (2013).

27 Verbych S, Bryk M, Chornokur G and Fuhr B, Removal of copper(II) from aqueous solutions by chitosan adsorption. Sep Sci Technol 40:1749-1759 (2013).

28 Igberase E, Osifo P and Ofomaja A, Chromium (VI) ion adsorption by grafted cross-linked chitosan beads in aqueous solution - a mathematical and statistical modeling study. Environ Technol 38:3156-3166 (2017).

29 Apiratikul R and Pavasant P, Batch and column studies of biosorption of heavy metals by Caulerpa lentillifera. Bioresour Technol 99:2766-2777 (2008).

30 Das B, Mondal NK, Roy P and Chattoraj S, Application of response surface methodology for hexavalent chromium adsorption onto alluvial soil of Indian origin. Int J Environ Pollut Solution 2:72-87 (2013).

31 Kobya M, Demirbas E, Gebologlu U, Oncel MS and Yildirim Y, Optimization of arsenic removal from drinking water by electrocoagulation batch process using response surface methodology. Desalin Water Treat 51:6676-6687 (2013). 